\title{
COMPARATIVE STUdy ON VEHIClE DETECTION TECHNIQUES IN AERIAL SURVEILlANCE
}

\author{
Selvakumar $\mathrm{S}^{1}$ and Kalaivani. $\mathrm{S}^{2}$ \\ ${ }^{1}$ Department of Computer Science and Engineering, P.B college of Engineering, \\ Chennai. \\ Selva.gingee@gmail.com \\ ${ }^{2}$ SITE,VIT University, Vellore
}

\begin{abstract}
Aerial surveillance system becomes a great trendy on past decades. Aerial surveillance vehicle tracking techniques plays a vital role and give rising to optimistic techniques continuously. This system can be very handy in various applications such as police, traffic monitoring, natural disaster and military. It is often covers large area and providing better perspective of moving objects. The detection of moving vehicle can be both from the dynamic aerial imagery, wide area motion imagery or images under low resolution and also the static in nature. It has been very difficult issue whether identify the object in the air view, the camera angles, movement objects and motionless object. This paper deals with comparative study on various vehicle detection and tracking approach in aerial videos with its experimental results and measures working condition, hit rate and false alarm rate.
\end{abstract}

\section{KEYWORDS}

Aerial surveillance, Vehicle Detection, Linear SVM Classification, Boosting HOG, Dynamic Baysian Network, Feature based detection.

\section{INTRODUCTION}

In recent years, there is a budding awareness in aerial surveillance. The growth of vehicle in roadway network has mandatory for transport organization agencies to relay advanced technologies to take superior decisions. This system can successfully monitor and support the tracking of the adversity areas. This system can be used for tracking moving vehicles or objects to avoid traffic jam and security enforce. Compared with land plane monitoring, airborne monitoring is more compact for surveillance of hasty moving objects and it cover wide area with low cost. Therefore, aerial surveillance becomes outstanding supplements of land plane surveillance system.

Over large urban areas with multifaceted traffic patterns, detection technologies which provide more absolute sampling capabilities can add an additional layer of traffic information to data acquired from direct or aerial point sensors. The aerial point sensors are more effective than direct point sensors. It covers large number of moving objects in ground plane and tracks the moving objects or vehicles easily.

Sometimes, aerial videos not in high resolution and also tilting of images are very difficult to handle the classification that situation approaches need to improve the technologies under low resolution images. This comparative study encompasses all the technologies which are used to detect vehicle in aerial surveillance based on strengths and weaknesses. 
International Journal on Cybernetics \& Informatics ( IJCI) Vol.2, No.4, August 2013

There are various types of approaches in aerial surveillance; one of the most common approaches is vision based. This approach more often used to analysis vehicle from aerial images or videos. The vision of vehicle will differ according to the camera points, illumination conditions and backdrop situations. Plenty of examine has been done in vehicle detection from airborne videos Hinz and Baumgarter [7] proposed a hierarchical illustration that portray levels of details from moving vehicle features. This method based on cascade classifier has manufacture lot of miss identifications of moving object. Luo-wei tsai, Jun-wei hsieh et al [3] proposed a new detection method using color transform model. This method is not correctly fit for moving vehicle but it's good for static object.

Choi and yang [8] proposed a new algorithm for vehicle detection using symmetric property of car shapes. However, this produces a lot of miss detections because of symmetrical details of building or road markings. Hong, Ruan et al.[9] presented an EM(Expectation-Maximization) based on joint spatio-temporal multiframe information processing technique for the multiple target tracking. Three energy density functions are approximated by Gaussian mixtures and estimated by a joint EM estimation. But these approach lots miss detection and also not worked in the rotated objects.

This paper provides the comparative study on technical analysis of existing methods which is extended to overcome the disadvantages of the techniques mentioned earlier.

\section{DETECTION USING OBJECT BASED APPROACH}

Ashley C. Holt, Edmund Y.W. Seto et al [1] which presents object oriented approach for detecting and classifying vehicles from high-resolution aerial videos. This approach has three steps for detecting the vehicles 1.segmentation 2.trainning 3.validation. For first step it takes some training images from total number of aerial view images depending upon time or number of frames. Then it proceed with optimization of segmentation parameters for segmentation and is repeated for training samples which involve multi - resolution segmentation and spectral difference segmentation then it transfer to validation part of object accuracy assessment with the training samples. In this model the circumstance of applicability to high spatial resolution tenuously sensed data, and to address the need for a quantitative, user-supervised method for choosing best segmentation parameters. It developed an objective metric which is the number of training object matched with maximize area matched and which is minimizes below and over segmentation for preferred images in objective primitives. By using this method the authors identify good result for static and gray scale images.

\section{DETECTION USING COLOR TRANSFORM MODEL}

Luo-wei tsai, Jun-wei hsieh et al [3] proposed a new method for vehicle detection using color transform model and edge map. This method introduces different phases for detection. In the first phase a color transform model recognize vehicle pixels from the image backgrounds. This technique reduced number of random samples unlike previous methods it takes only less number of images for training. All color participation pixels are projected on color space. In the second phase a classification is carried out using Bayesian classifier which detects pixels corresponding to the vehicle or not and it generates different vehicle premise for each detected vehicles.

The final phase is validation of hypothesis by coefficient of wavelet transform, edges and corners of images. This method is efficient and takes less number of training samples and results in accurate vehicle detection on static images. 


\section{VEHICLE DETECTION IN WIDE AREA MOTION IMAGERY}

Nowadays moving vehicle detection is extremely promising applications in wide area motion imagery. This area increases the challenging factors and demands. The authors relay on a new vehicle detection framework which is slot in the vista circumstance too.

Hansen et al [5] proposed an affine model for operation of motion detection. Then it recognizes the vehicle by the trained classifier. The second step is most important which involved usage of scene context information. Then next step deals with gradient distribution and shapes. For the classification the authors used support vector machine (SVM) along with some features histogram of oriented gradient (HOG). Finally road context extraction used to categorization multiobject tracking.

\section{VEHICLE DETECTION MOTION ANALYSIS IN LOW ALTITUDE AIRBORNE VIDEOS}

Xianbin Cao, Changxia Wu et al [4] proposed an extension of SVM classifier added new features of HOG overcoming the disadvantages that are called boosting light and pyramid sampling histogram of oriented gradients (bLPS-HOG). This classifier is used to detect vehicle in low height airborne videos. This approach is divided into two phases which include classifier training and feature description.

The SVM used for vehicle detection because SVM able to produce optimal solution and feature description used to distinguish vehicle from other objects. New bLPS - HOG results to decrease dimensionality of input features of SVM. It increases the speedup of vehicle detection process and better symbolize of global features of vehicles. The vehicles are detected by each frame after that vehicles correlated to get together across the frames movement analysis.

The STARS method applied for successive frames to found the correlation of vehicles to refine the detection results for motion analysis. This approach extremely works on real time applications.

\section{FUTURE BASED APPROACH FOR LOW RESOLUTION AERIAL IMAGERY}

Samir Sahli, Yueh Ouyang et al [6] proposed a new feature based method for vehicle detection in low resolution aerial imagery. This approach uses scale - invariant feature transform (SIFT) for extract key points in the images. The SVM used to predict if the SIFT key points belongs to vehicle structure or not in the image. The SIFT is a graphical operations like translation, rotation, scaling and enlightenment changes is mainly well-organized to process with the normal open-air and simply pretentious by a noise and small distortion.

Finally, Affinity Propagation (AP) algorithm used to separate clustering of SIFT key points in the images which already classified by SVM. AP based on this switch over facts at the foundation of the data inhabitants to induce a global partition. It is a constraint on the spatial expansion of the clusters in the AP execution to avoid the clusters of SIFT key points crossing over multiple vehicles. 
International Journal on Cybernetics \& Informatics ( IJCI) Vol.2, No.4, August 2013

\section{VEHICLE DETECTION USING DYNAMIC BAYESIAN NETWORK}

Hsu-Yung Cheng, Chih-Chia Weng et al [2] proposed a novelty of vehicle detection in aerial surveillance by using dynamic Bayesian network. This approach used a model pixelwise classification for vehicle detection in aerial surveillance. This method as new one to all other either region based or sliding window based. This framework has two phases to implement vehicle detection 1. Training phase and 2.Detection phase.

In Training Phase extract the multiple features of images like edge detection, corner detection and color transformation with sample training images. After to apply dynamic Bayesian network to classify vehicle color and background color of the image frames. The DBN used to classify vehicle color and non vehicle color by pixelwise classification. In detection phase, the background removal and feature extraction process for all image frames. Classification process easily identifies the vehicle by comparing the result of training and detection phase.

Finally post processing model apply for morphological operations to all detected frames. This approach is robust on different height of camera, tilting of pictures and rotated vehicles with fewer false alarms.

\section{COMPARISON AND DISCUSSION}

Comparative studies on different techniques to detect vehicles in aerial view videos are elaborated and summarized in table I. This table explores the merit and issues on each technique with respect to their technologies involved, amount of training samples, speed, working constriction and false alarm rate. Finally the SVM with SIFT and DBN is substantial reduce false alarm rate compare with other technologies.

In this study, the vehicle detection techniques strengths and weaknesses present in table II. The results show how the methods are achieved vehicle detection in aerial images and incredibly much useful which is the best approach to compare of those six methods. The performance measures such as hit rate and false alarm rates are compared for the investigate method of these technologies. The detection accuracy of all these technology present in table III.

Analysis of all the six methods Dynamic Bayesian Network and Context Driven approaches having maximum accuracy $96 \%$ and $95 \%$. In other hand false alarm rate is the big issue to find quality detection method which approach having less false alarm rate that helps to researchers find ideal approach for vehicle detection in aerial surveillance. 
International Journal on Cybernetics \& Informatics ( IJCI) Vol.2, No.4, August 2013

Table 1. Comparison of six vehicle detection method in aerial surveillance

\begin{tabular}{|l|l|l|l|l|}
\hline Method & $\begin{array}{l}\text { Technologies } \\
\text { involved }\end{array}$ & $\begin{array}{l}\text { Amount of } \\
\text { training } \\
\text { samples }\end{array}$ & $\begin{array}{l}\text { Speed up with } \\
\text { large images or } \\
\text { videos }\end{array}$ & $\begin{array}{l}\text { Working } \\
\text { constriction }\end{array}$ \\
\hline $\begin{array}{l}\text { Object based } \\
\text { approach }\end{array}$ & $\begin{array}{l}\text { Object oriented } \\
\text { target detection }\end{array}$ & $\begin{array}{l}\text { Large amount } \\
\text { of training } \\
\text { sample }\end{array}$ & $\begin{array}{l}\text { Works very } \\
\text { slow on large } \\
\text { number of } \\
\text { imnman }\end{array}$ & $\begin{array}{l}\text { High resolution } \\
\text { images }\end{array}$ \\
\hline $\begin{array}{l}\text { Color transform } \\
\text { model }\end{array}$ & $\begin{array}{l}\text { Normalized edge } \\
\text { and color Map }\end{array}$ & $\begin{array}{l}\text { High training } \\
\text { sample } \\
\text { resolution } \\
\text { images }\end{array}$ & $\begin{array}{l}\text { Bright and sunny } \\
\text { images }\end{array}$ \\
\hline $\begin{array}{l}\text { Context driven }- \\
\text { Wide area motion } \\
\text { imagery }\end{array}$ & SVM and HOG & $\begin{array}{l}\text { Columbus } \\
\text { large image } \\
\text { format (CLIF) }\end{array}$ & $\begin{array}{l}\text { Low on week } \\
\text { contrast images }\end{array}$ & $\begin{array}{l}\text { Work both high } \\
\text { and low lighting } \\
\text { images }\end{array}$ \\
\hline $\begin{array}{l}\text { Detection and } \\
\text { motion analysis in } \\
\text { lowaltitude } \\
\text { airborne videos }\end{array}$ & $\begin{array}{l}\text { SVM with bLPS } \\
\text { HOG }\end{array}$ & $\begin{array}{l}\text { Needlarge } \\
\text { amount video } \\
\text { taken }\end{array}$ & $\begin{array}{l}\text { Less working } \\
\text { speed }\end{array}$ & $\begin{array}{l}\text { Work in city } \\
\text { view videos }\end{array}$ \\
\hline $\begin{array}{l}\text { Feature based } \\
\text { Approach }\end{array}$ & SIFT with AP & $\begin{array}{l}\text { Small amount } \\
\text { training } \\
\text { sambles }\end{array}$ & $\begin{array}{l}\text { Average } \\
\text { detection rate }\end{array}$ & $\begin{array}{l}\text { Work } \\
\text { irrespective }\end{array}$ \\
\hline $\begin{array}{l}\text { Dynamic Bayesian } \\
\text { Network }\end{array}$ & $\begin{array}{l}\text { Pixelwise } \\
\text { classification } \\
\text { (DBN) }\end{array}$ & $\begin{array}{l}\text { Much faster } \\
\text { than other }\end{array}$ & $\begin{array}{l}\text { All camera angle } \\
\text { and tilting images }\end{array}$ \\
\hline
\end{tabular}

Table 2. Based on strength and weakness of six vehicle detection approaches

\begin{tabular}{|c|c|c|}
\hline Method & Strengths & Weaknesses \\
\hline Object based approach & $\begin{array}{l}>\text { Object based approach } \\
>\text { Easy to learn }\end{array}$ & $\begin{array}{l}\text { Not working in } \\
\text { low resolution } \\
\text { images } \\
\text { It is only for atatic } \\
\text { object images }\end{array}$ \\
\hline Color transform model & $\begin{array}{l}\text { Good result for sunny } \\
\text { images }\end{array}$ & $\begin{array}{l}\text { High aample } \\
\text { training rate } \\
\text { Not working in } \\
\text { moving object. }\end{array}$ \\
\hline $\begin{array}{l}\text { Context driven - Wide } \\
\text { area motion imagery }\end{array}$ & $\begin{array}{l}>\text { It redice the context } \\
\text { extraction } \\
>\text { working under low } \\
\text { resolution images also }\end{array}$ & $\begin{array}{l}\text { It is not working } \\
\text { on rotated } \\
\text { vehicles or tilting } \\
\text { images }\end{array}$ \\
\hline $\begin{array}{l}\text { Detection and motion } \\
\text { analysis in low altitude } \\
\text { airborne videos }\end{array}$ & $\begin{array}{l}\text { Very less training } \\
\text { asmple required }\end{array}$ & $\begin{array}{l}\text { False alarm rate in } \\
\text { higher aide }\end{array}$ \\
\hline Feature based & $\begin{array}{l}>\quad \text { Small amount of } \\
\text { training amples only } \\
>\quad \text { Working in low } \\
\text { resolution images }\end{array}$ & $\begin{array}{l}\text { High } \\
\text { computational } \\
\text { complexity for } \\
\text { color transform }\end{array}$ \\
\hline Dynamic Bayesian Network & $\begin{array}{l}>\quad \text { Very small amount } \\
\text { training samples } \\
>\text { Pixelwise classification } \\
>\text { working under fast } \\
\text { moving and rotated } \\
\text { vehicles }\end{array}$ & 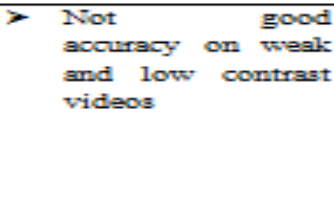 \\
\hline
\end{tabular}


International Journal on Cybernetics \& Informatics ( IJCI) Vol.2, No.4, August 2013

Table 3. Vehicle detection accuracy and miss rate for all six detection methods

\begin{tabular}{|l|l|l|}
\hline Vehicle detection method & $\begin{array}{l}\text { Hit rate (or) } \\
\text { Accuracy }\end{array}$ & $\begin{array}{l}\text { Miss rate (or) } \\
\text { false alarm }\end{array}$ \\
\hline Object based approach & $87.5 \%$ & $12 \%$ \\
\hline Color transform model & $94.8 \%$ & $8.5 \%$ \\
\hline $\begin{array}{l}\text { Context driven - Wide area motion } \\
\text { imagery }\end{array}$ & $95 \%$ & $7.17 \%$ \\
\hline Vehicle detection method & $\begin{array}{l}\text { Hit rate (or) } \\
\text { Accuracy }\end{array}$ & $\begin{array}{l}\text { Miss rate (or) } \\
\text { false alarm }\end{array}$ \\
\hline $\begin{array}{l}\text { Detection and motion analysis in low } \\
\text { altitude airborne videos }\end{array}$ & $90 \%$ & $10 \%$ \\
\hline Feature based & $92.16 \%$ & $7.26 \%$ \\
\hline Dynamic Bayesian Network & $96 \%$ & $6.5 \%$ \\
\hline
\end{tabular}

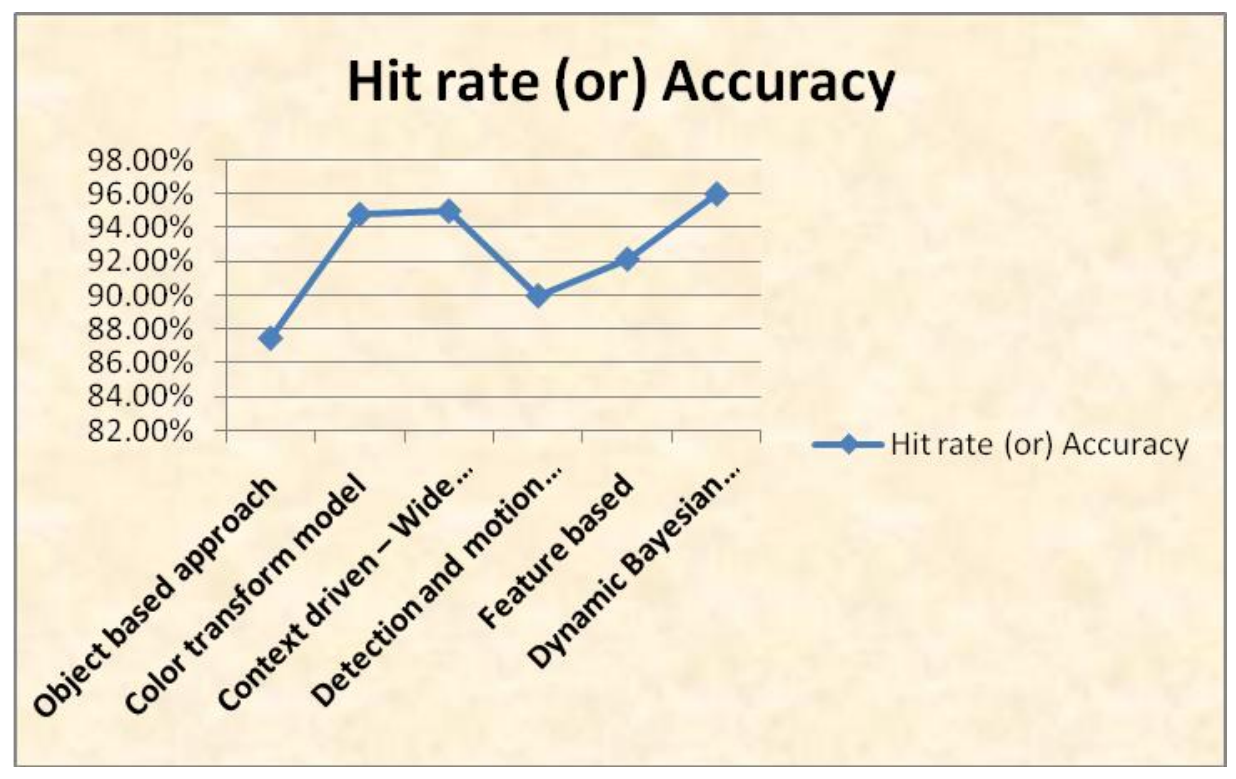

Fig 1. Vehicle detection Accuracy 


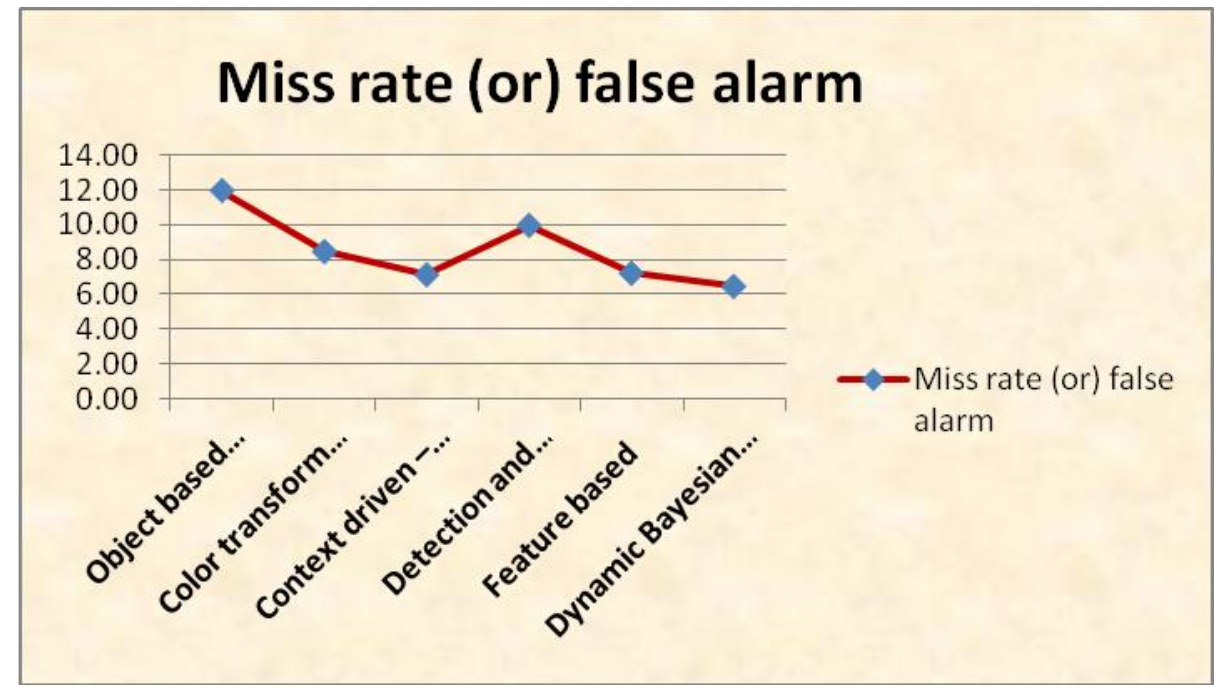

Fig 2. False Alarm rates

Compared to all other methods false alarm rate slightly higher side in object based approach and detection and motion analysis approach. DBN and future based approaches having very less false alarm rate.

\section{CONCLUSION}

In this paper, the comparative study on various vehicle detection techniques is clearly demonstrated and results are compared with appropriate measures. Each technique results in efficient vehicle detection in aerial view images. The main objective of this paper is to explore a supreme approach of nearly high detection rate and low false alarms of different techniques. An ideal approach requires low training samples. In our observation normalized color and edge map

need large number of training samples. In spite of SIFT with AP and DBN methods need very fewer sample training images for classification. Other two methods used to HOG feature along with SVM for detection and classification but it reduce detection speed and accuracy. The comparative points to the facts of vehicle detection using dynamic Bayesian networks much suitable for all the conditions and it works well in small training dataset and produces low false alarms .It works under the different camera heights, different angle, tilting images and rotated vehicles.

\section{REFERENCES}

[1] Ashley C. Holt, Edmund Y.W. Seto, Tom Rivard, and Peng Gong, "Object-based Detection and Classification of Vehicles from High-resolution Aerial Photography," in Photogrammetric Engineering \& Remote Sensing, 871-880, July 2009.

[2] Hsu-Yung Cheng, Chih-Chia Weng, and Yi-Ying Chen," Vehicle Detection in Aerial Surveillance Using Dynamic Bayesian Networks",IEEE Transactions on image processing ,Vol.21,No.4,April 2012.

[3] Luo-wei tsai, Jun-wei hsieh, member, IEEE, and Kuo-chin fan, member, IEEE, "Vehicle detection using normalized color and edge map", IEEE Transactions On Image Processing, vol. 16, no. 3, March 2007.

[4] Xianbin Cao, Changxia Wu, Jinhe Lan, Pingkun Yan, and Xuelong Li, "Vehicle Detection and Motion Analysis in low-Altitude Airborne Video Under Urban Environment", IEEE Transactions on circuit and systems for video technology, Vol.21, NO.10, October 2011. 
International Journal on Cybernetics \& Informatics ( IJCI) Vol.2, No.4, August 2013

[5] M. Hansen, P. Anadan, K. Dana, G. van de Wal, P. Burt, "Real-time scene stabilization and Mosaic Construction", Proc of IEEE CVPR,1994, 54-62).

[6] Samir Sahli, Yueh Ouyang, Yunlong Sheng, Daniel A. lavigne "Robust vehicle detection in lowresolution aerial imagery" a Image Science group.

[7] S. Hinz and A. Baumgartner, "Vehicle detection in aerial images using generic features, grouping, and context," in Proc. DAGM-Symp., Sep. 2001, vol. 2191, Lecture Notes in Computer Science, pp. $45-52$.

[8] J. Y. Choi and Y. K. Yang, "Vehicle detection from aerial images using local shape information," Adv. Image Video Technol., vol. 5414, Lecture Notes in Computer Science, pp. 227-236, Jan. 2009.

[9] L.Hong, Y.Ruan, W.Li, D.Wicker, J.Layne, "Energy based video tracking using joint target density processing with an application to unnamed aerial surveillance," in IET computer Vision ietcvi:20070017, Oct 2007.

[10] R. Lin, X. Cao, Y. Xu, C.Wu, and H. Qiao, "Airborne moving vehicle detection for urban traffic surveillance,” in Proc. 11th Int. IEEE Conf. Intell. Transp. Syst., Oct. 2008, pp. 163-167. 